\title{
Met tyrosine kinase inhibitor, PF-234I066, suppresses growth and invasion of nasopharyngeal carcinoma
}

\author{
Yuanyuan Zhao',* \\ Jing Zhang ${ }^{2, *}$ \\ Ying Tian ${ }^{1, *}$ \\ Cong Xue' \\ Zhihuang $\mathrm{Hu}^{\prime}$ \\ Li Zhang ${ }^{1,3}$
}

'Department of Medical Oncology, Sun Yat-Sen University Cancer Center, State Key Laboratory of Oncology in South China, and Collaborative Innovation Center for Cancer Medicine, ${ }^{2}$ Department of Medical Oncology, the First Affiliated Hospital of Guang Zhou Traditional Chinese Medicine University, ${ }^{3}$ National AntiCancer Drug Research Centre, Sun Yat-Sen University Cancer Center, State Key Laboratory of Oncology in South China, and Collaborative Innovation Center for Cancer Medicine, Guangzhou, People's Republic of China

*These authors contributed equally to this work

Correspondence: Li Zhang

Department of Medical Oncology, Sun Yat-Sen University Cancer Centre, State Key Laboratory of Oncology in South China, 65I Dong Feng Road East, Guangzhou 510060, People's Republic of China

Tel +862087342288

Fax +86 2087343365

Email zhangli6@mail.sysu.edu.cn
This article was published in the following Dove Press journal:

Drug Design, Development and Therapy

26 August 2015

Number of times this article has been viewed

Purpose: We explored the effect of hepatocyte growth factor (HGF)/Met signaling pathway on nasopharyngeal carcinoma (NPC) cells in vitro and in vivo, and investigated the ability of Met tyrosine kinase inhibitor (TKI) to block HGF-induced biological signaling.

Experimental design: Met TKI inhibitor PF-2341066 alone, or in combination with cisplatin, was investigated for its ability to block HGF-induced signaling and biological effects in vitro and in vivo. HGF/Met expression and activation of signaling in NPC cells were detected by using Western blot and immunohistochemistry. Biological evaluation, including wound healing, cell proliferation, and invasion of NPC cells, was also examined, and the correlation between HGF/Met expression of primary and metastatic tumor in NPC patients and clinical prognosis were also analyzed.

Results: Met TKI inhibitor, PF-2341066, inhibited growth of NPC cells in vivo with half maximal inhibitory concentration of $0.79 \pm 0.21 \mu \mathrm{mol} / \mathrm{L}$, and suppressed invasion and migration of NPC cells; also, the inhibition of PF-2341066 was synergized with cisplatin treatment. Compared with the control group, Met TKI inhibited metastasis of transplanted NPC in nude mice (the number of live metastases [mean $\pm \mathrm{SD}$ ]: $5.8 \pm 2.2$ versus $11.8 \pm 2.2, P=0.03$; the number of lung metastases: $2.3 \pm 1.5$ versus $5.3 \pm 0.9, P=0.06$ ). HGF was widely expressed in both primary and metastatic lesions while Met expression of metastatic lesions was higher than that of primary lesions (primary lesions: 24.7\%; liver metastases: 40\%; lung metastases: 29\%; lymph node metastases: $29 \%, P<0.05)$, and overall survival of NPC patients with higher expression of Met was shorter $(P=0.13)$.

Conclusion: Our results demonstrated that HGF/Met signaling promoted NPC growth, further resulting in metastasis and poor prognosis. Met TKI, PF-2341066, showed potent antitumor activity in vivo and in vitro which was enhanced by combination with cisplatin. Our study implied that HGF/Met signaling was the potential therapeutic target in NPC, and blockage of the signaling could prevent growth and metastasis of NPC and derive clinical benefit.

Keywords: HGF/Met pathway, proliferation, invasion

\section{Introduction}

Nasopharyngeal carcinoma (NPC) is a squamous epithelial cancer arising from the lateral wall surface of nasopharynx, and which is distinctive in terms of ethnic and geographic distribution. ${ }^{1-3}$ NPC can be classified into three subtypes including type I (keratinizing squamous carcinoma), type II (differentiated nonkeratinizing carcinoma), and type III (nonkeratinizing carcinoma with less differentiation). ${ }^{4}$ Type III is the most common in epidemic areas and closely related to EpsteinBarr virus infection. ${ }^{5,6}$ However, the NPC of type III is more sensitive to radiotherapy and chemotherapy than other head and neck cancers, and radiotherapy and concurrent chemoradiotherapy is considered to be primary option of treatment. ${ }^{7}$ 
The 5-year survival rate of stage I and II NPC treated with radiotherapy is up to $90 \% .{ }^{8,9}$ However, the majority of NPC patients tend to be in the locally advanced stages or with distant metastasis (T3-4/N2-3) at initial diagnosis because the anatomical site of primary cancer is located in the silent painless area, ${ }^{10}$ and the 5-year survival rate of advanced NPC ranges from $50 \%$ to $70 \% .^{11,12}$ The main factors which affect survival of NPC patients are recurrence and distant metastases. ${ }^{13}$ Further, chemotherapy is poorly tolerated, and it was reported that only $45 \%$ of patients fully accomplished the planned chemotherapy because of substantial toxicities from concurrent chemoradiotherapy. ${ }^{14}$ Thus, treatment of NPC remains a challenge. Targeted therapy promised a novel field of tumor researches, providing new hope. However, limited valuable discoveries were made. ${ }^{15-19}$ Recently, numerous discoveries have focused on the role of hepatocyte growth factor (HGF)/Met signaling in cancers. $\mathrm{HGF} / \mathrm{Met}$ activation results in activation of downstream signaling which leads to changes in cell behavior such as proliferation, survival, invasiveness, and angiogenesis. ${ }^{20}$ Studies and clinical investigation provided powerful and comprehensive evidence that activation of $\mathrm{HGF} / \mathrm{Met}$ kinase plays a significant role in a variety of tumors including lung cancer, gastric cancer, head and neck squamous cell cancer (HNSCC), breast cancer, and pancreatic cancer. ${ }^{21}$ However, there are few researches on the role of HGF/Met signaling in development of NPC. PF-2341066 is a potent, orally bioavailable, ATP-competitive small molecule inhibitor targeting the catalytic activity of Met kinase. Studies showed that PF-2341066 could inhibit the growth, invasion, metastasis, and angiogenesis of tumors by repressing Met phosphorylation. ${ }^{22}$ Our study aimed to explore the potential effect of the Met tyrosine kinase inhibitor, PF-2341066, on the biology of NPC, and to detect the HGF/Met expression in primary and metastatic lesions of NPC, which will provide a preclinical clue for Met-targeted therapy in NPC patients.

\section{Materials and methods}

\section{Patients and specimens}

Tumor tissues were obtained from NPC patients in our hospital during 2000-2009. Eighty-nine specimens were from primary tissues of patients who were diagnosed with local advanced tumor, and received radiotherapy later. Fifty-two metastatic samples were from patients who accepted metastases resection surgery. All patients consented to tissue collection for research in the development of oncology. Informed consent was obtained from all study subjects before sample collection. The Ethics committee of Sun Yat-Sen University Cancer Center approved the study protocol, and all patients provided written informed consent.

\section{Materials and reagents}

All of the NPC cell lines including CNE-1, CNE-2, HNE-1, SUNE-1, and the normal epithelial cell line NP69 were from the key laboratory of the Sun Yat-Sen University cancer center (Guangzhou, People's Republic of China). All NPC cells were cultured in RPMI 1640 medium supplemented with 10\% fetal bovine serum (FBS) (Hyclone, Logan, UT, USA), $100 \mathrm{U} / \mathrm{mL}$ penicillin, and $100 \mu \mathrm{g} / \mathrm{mL}$ streptomycin (Thermo Fisher Scientific, Waltham, MA, USA). NP69 cells were maintained in serum-free medium (STEMCELL Technologies, Vancouver, BC, Canada). These cells were used within passage number four to six. All cells were cultured at $37^{\circ} \mathrm{C}$ in a $5 \% \mathrm{CO}_{2}$-humidified incubator.

Antibodies used in this study included anti-Met antibodies for immunohistochemistry (Ventana, Harvard, MA, USA) and Western blot (Santa Cruz Biotechnology Inc., Dallas, TX, USA). Anti-phospho-Met (Upstate, NY, USA), anti-HGF, anti-AKT, anti-phospho-AKT, anti-MAPK, antiERK, anti-phospho-ERK, anti-vimentin, anti-Snail, and anti-glyceraldehyde 3-phosphate dehydrogenase (GAPDH) for Western blot were purchased from the same company (CST, Danvers, MA, USA), while Anit-phospho-Met were purchased from another company (Upstate, Syracuse, NY, USA). PF-2341066 was dissolved in dimethyl sulfoxide, allotted, and stored at $-20^{\circ} \mathrm{C}$ for use in vitro while dissolved in water for intragastric administration.

\section{Cell proliferation assay}

HNE-1 cells were plated in 96-well plates at $3 \times 10^{3}$ cells/ well and grew in complete medium after serum-starving for 12 hours to minimize the influence of serum. After adherence, cells were treated with PF-2341066, cisplatin, or combination for 48 hours; $10 \mu \mathrm{L}$ of Cell Counting Kit-8 (Dojindo, Kumamoto, Japan), was added to each well and incubated at $37^{\circ} \mathrm{C}$ for 2 hours. The optical density of the contents of each well was detected by using a microplate reader set at $450 \mathrm{~nm}$. The percentage of cell death was calculated with the equation:

$$
\text { Cell death ratio }=1-\text { cell viability ratio }
$$

\section{Scratch wound assay}

Diluted HNE-1 cells in log growth phase were plated in sixwell plates for 24 hours and wounds were generated using sterile $200 \mu \mathrm{L}$ pipet tips. Then, the cells were exposed to specific treatments and grew for 48 hours. Wound closure images were captured using an Olympus IX71 at 10× magnification and the migration distance was measured and analyzed. 


\section{Matrigel invasion assay}

Matrigel invasion was determined using an available kit (Transwell; BD Biosciences, San Jose, CA, USA) according to the kit instructions. Briefly, HNE-1 cells were suspended in serum-free medium at a density of $2 \times 10^{5} \mathrm{cells} / \mathrm{mL}$. One hundred microliters of suspended cells and $100 \mu \mathrm{L}$ of medium with or without drugs were added to each of the upper chambers. The cell-containing chambers were immersed in the bottom chambers filled with medium containing 10\% FBS and were incubated for 40 hours at $37^{\circ} \mathrm{C}$. Non-invading cells retained in the upper chamber were removed by cotton swab, while the invading cells were fixed with $10 \%$ methanol and stained with $0.1 \%$ crystal violet, and the number of migrated cells was quantitated using image-Pro plus software over a random composite of five microscopic images (N1, N2, N3, $\mathrm{N} 4, \mathrm{~N} 5$ ), and the values were averaged as: $\mathrm{N}_{1}+\mathrm{N}_{2}+\mathrm{N}_{3}+$ $\mathrm{N}_{4}+\mathrm{N}_{5} / 5$.

\section{Western blot}

HNE-1 cells were plated with low-serum medium (5\% FBS). Culture medium was diluted with different concentrations of drug, and $50 \mathrm{ng} / \mathrm{mL}$ HGF was then added directly to the cells and incubated at $37^{\circ} \mathrm{C}$. After 24 hours, cells were harvested, washed twice with pre-cold phosphate buffer solution, and lysed using lysis buffer (No 9803; CST) for $15 \mathrm{~min}$ at $4^{\circ} \mathrm{C}$. The undissolved material was removed by centrifugation at $4^{\circ} \mathrm{C} 14,000 \mathrm{rpm}$ for 15 minutes. An equal amount of cell extracts was separated by $10 \%$ sodium dodecyl sulfatepolyacrylamide gel electrophoresis gel and transferred to polyvinylidene fluoride membranes. The transferred membranes were probed overnight at $4^{\circ} \mathrm{C}$ with antibodies against Met, p-Met, AKT, p-AKT, ERK, p-ERK, vimentin, Snail, and GAPDH. Immunoreactivity was detected using anti-mouse or anti-rabbit IgG conjugated with horseradish peroxides, visualized by Electro-Chemi_Luminescence reagents (Merk, Kenilworth, NJ, USA), and exposed on X-ray films.

\section{Immunohistochemistry}

Immunohistochemical stains were carried out by using an automated Nexus staining apparatus (Ventana Medical Systems, Harvard, MA, USA) following the manufacturer's guidelines. Antibodies to Met (1:200), HGF (1:250), p-AKT (1:150), and AKT (1:200) were used as the primary antibodies. Stained slides were observed and imaged by microscope. Immunohistochemical evaluation was performed using the histologic score (H-score) and reviewed by a head and neck cancer pathologist. Five fields (under a $\times 40$ objective) from each slide were randomly selected, and the percentage of stained cells in each field were calculated. The staining intensity was scored as 0 (none), 1 (weak), 2 (moderate), or 3 (strong).

$\mathrm{H}$-score $=$ The percentage of stained cell $\times$ staining intensity $\times 100 \%$

According to receiver operating characteristic curve, $\mathrm{H}$-score $\geq 100$ was considered as positive.

\section{In vivo studies}

Four- to 6-week-old male BALB/c (nu/nu) nude mice (specific pathogen-free, certificate number: 4304701265) were obtained from Hunan SJA Laboratory Animal Co., Ltd. (Changsha, Hunan, People's Republic of China), and maintained in the Animal Center of the north campus, Sun Yat-Sen University, under specific pathogen-free conditions. All experiments were conducted in accordance with National Institute of Health guidelines for the care and use of laboratory animals. HNE-1 cells $\left(2 \times 10^{6}\right)$ were implanted into the right flank of each mouse. After 3 days, a subcutaneous nodule began to grow up indicating that the xenograft models were successful. Mice were divided into four groups randomly and kept for 3 weeks. The PF-2341066 group was given $50 \mathrm{mg} / \mathrm{kg} / \mathrm{d}$ PF-2341066 by oral gavages; the cisplatin group was injected intraperitoneally with $1 \mathrm{mg} / \mathrm{kg} / \mathrm{d}$ cisplatin; the combination group was given both PF-2341066 and cisplatin with the same concentration; the control group was given gavages with sterile water and injected with normal saline. Tumor volume and mouse weight were measured every 2 days. After 3 weeks, mice were sacrificed and tumors were resected. Tumor samples were divided into two parts. Half was fixed in 10\% formalin and paraffin embedded for hematoxylin and eosin staining and immunohistochemistry. The other half was snap frozen in liquid nitrogen and maintained at $-80^{\circ} \mathrm{C}$ for Western blot analysis.

\section{Statistical analysis}

Differences were evaluated using Statistical Package for Social Science software (SPSS, Version 16.0; SPSS Inc., Chicago, IL, USA). Cell culture-based assays were repeated at least three times; data were expressed as mean \pm standard deviation, and Student's $t$-test and the $\chi^{2}$-test were used respectively. $P<0.05$ was considered to be statistically significant.

\section{Results}

PF-2341066 alone or combination with cisplatin inhibited the proliferation of HNE-1 cells in vitro. We tested cell viability by CCK- 8 kit. The half maximal inhibitory concentration of PF-2341066 alone is $0.79 \pm 0.21 \mu \mathrm{mol} / \mathrm{L}$, while combination with cisplatin is $0.41 \pm 0.13 \mu \mathrm{mol} / \mathrm{L}$. The inhibition rate 
A

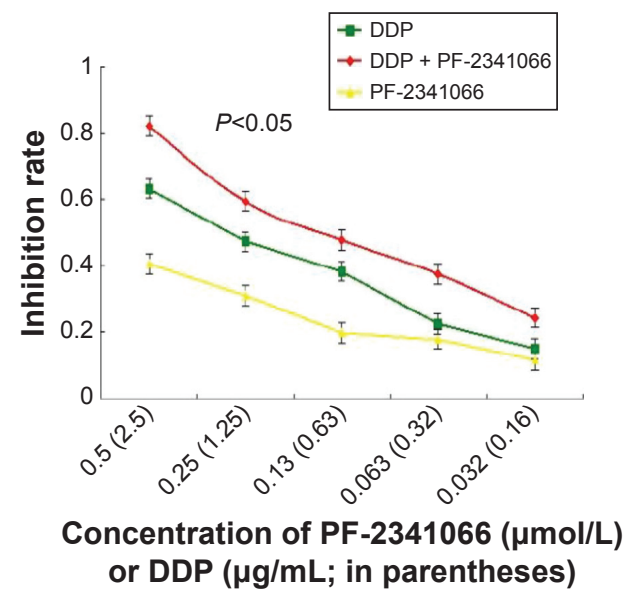

B

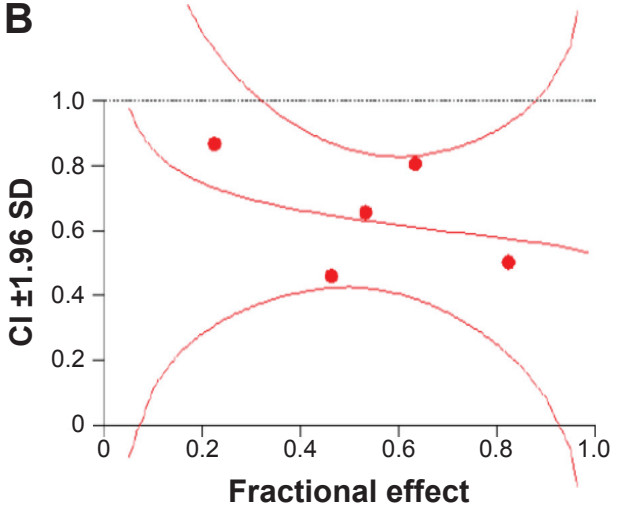

Figure I PF-2341066 alone or combination with cisplatin inhibited the proliferation of HNE-I cells in vitro.

Notes: (A) PF-234I066 alone or in combination with DDP inhibited the proliferation of HNE-I cells. The half maximal inhibitory concentration of PF-234I066 alone is $0.79 \pm 0.21 \mu \mathrm{mol} / \mathrm{L}$, while in combination with DDP is $0.4 \mathrm{I} \pm 0.13 \mu \mathrm{mol} / \mathrm{L}$. (B) PF-234I 066 showed a synergistic effect in combination with DDP. The inhibition rate increased by $23.4 \%$ and showed certain synergistic effects by using CalcuSyn.

Abbreviations: $\mathrm{Cl}$, confidence interval; DDP, cisplatin; SD, standard deviation.

increased by $23.4 \%$ and showed certain synergistic effects (Figure $1 \mathrm{~A}$ and $\mathrm{B}$ ).

PF-2341066 inhibited the migration and invasion ability of HNE-1 cells.

The migration and invasion ability of NPC cells was highly initiated by HGF, and PF-2341066 could abrogate the biological responses induced by HGF in HNE-1 cells. Distance of NPC cell scramble at 48 hours was $0.99 \pm 0.11 \mathrm{~mm}$ in plates of PF-2341066 alone, $0.67 \pm 0.07 \mathrm{~mm}$ in cisplatin alone, and $0.33 \pm 0.05 \mathrm{~mm}$ in combination, $(P<0.05)$ (Figure 2A). A similar result was observed using Matrigel invasion assay: a statistically significant reduction of percent of cell invasion was demonstrated $(P<0.001)$ after treatment with both PF-2341066 and cisplatin for 48 hours (Figure 2B).

PF-2341066 downregulated activation of Met signaling pathway in NPC cells.

We examined the total Met and phosphorylated Met in NPC cell lines and the normal epithelial cell line NP69 with or without drug treatment. We found that total Met protein expressed in all cells but phosphorylated Met was only detected in cancer cells (Figure 3A). As shown in Figure 3B, PF-2341066 inhibited Met phosphorylation, and two key downstream effector molecules of HGF/Met, AKT and ERK, were induced by HGF in a concentration-dependent fashion. The expression of Snail and vimentin were also inhibited, which was proved to be related with epithelial mesenchymal transition (EMT).

\section{The antitumor activity of PF-2341066 in vivo}

In in vivo test, PF-2341066 inhibited HNE-1 tumor xenograft growth in nude mice with $50 \mathrm{mg} / \mathrm{kg} / \mathrm{d}$, and inhibition rate was highest in the combination group $(P=0.03)$, while weight loss was almost the same $(P=0.77)$ (Figure $4 \mathrm{~A}$ and $\mathrm{B})$. Also, it was further confirmed that PF-2341066 inhibited not only the phosphorylation of Met, AKT, and ERK, but also enhanced inhibition of HGF/Met signaling pathway of cisplatin treatment (Figure 4C).

In in vivo study, we fixed lungs and livers of nodules and sectioned for hematoxylin and eosin staining. As shown in Table 1, PF-2341066 also inhibited the metastatic lesions of HNE-1 in vivo, especially hepatic metastases.

\section{Expression of HGF/Met in NPC primary lesions was distinctive compared to that of metastatic lesions}

We detected the expression of HGF/Met in 89 primary lesions and 52 metastatic lesions of NPC patients (Figure 5A); the clinical data are shown in Table S1. Our results indicated that HGF was widely expressed in NPC tissues, but the Met expression in primary lesions and metastatic lesions were significantly different. The Met expression was correlative to overall survival of NPC patients. The Met expression was higher with cases with poor overall survival $(P=0.13)$ (Figure 5B), and the Met expression of primary lesions was different from metastatic sites. Met expression in primary lesions was $24.7 \%$, while the expression of Met in liver, lung, and lymph node metastases was $40 \%, 29 \%$, and $29 \%$ respectively (Table 2 ).

\section{Discussion}

NPC is one of the common cancers in endemic areas with significant morbidity and mortality owing to its invasive phenotype and high metastatic potential. ${ }^{1-3,13}$ Further exploration into 
A

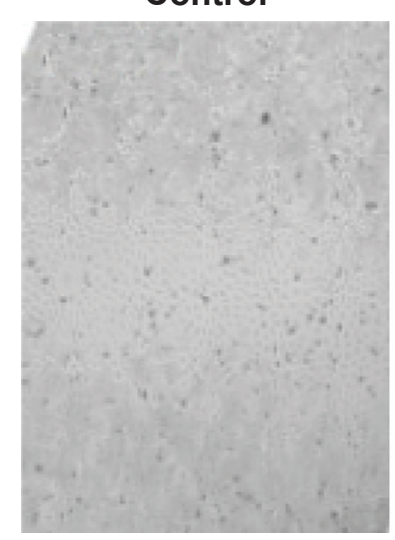

PF-2341066

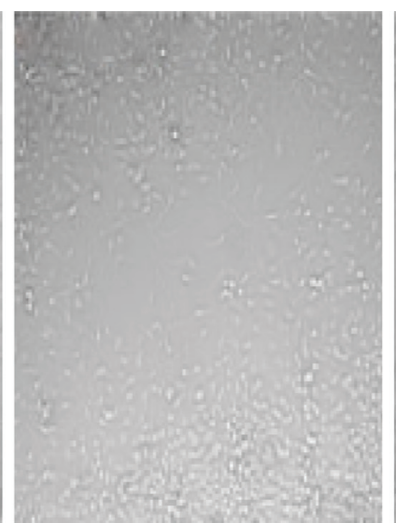

DDP

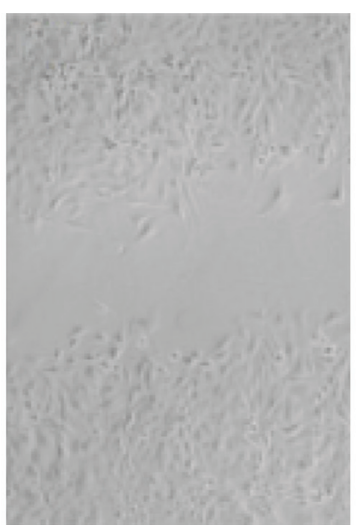

PF-2341066 + DDP

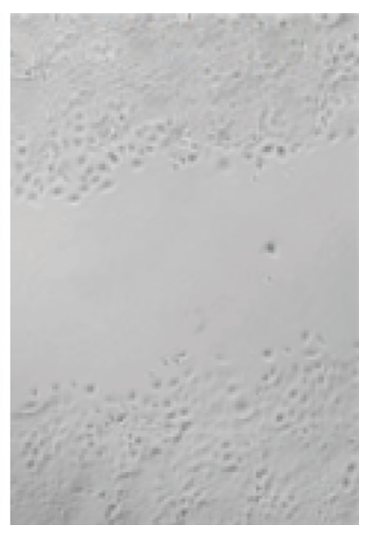

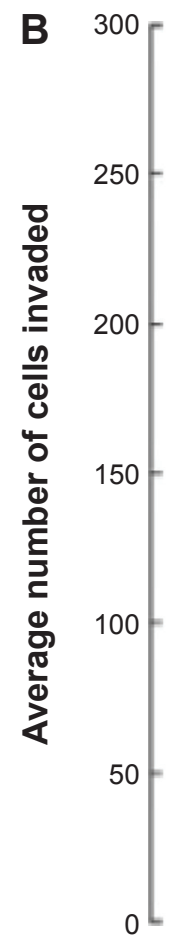

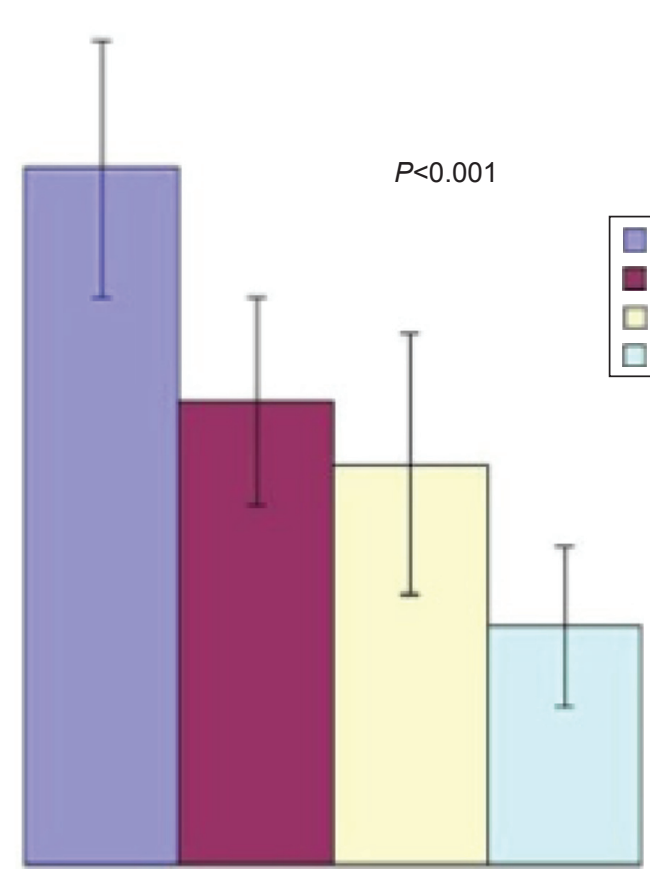

Figure 2 PF-2341066 inhibited wound closure and migration in NPC cell lines.

Notes: (A) PF-234I 066 inhibited migration of NPC cells. Diluted HNE-I cells in log growth phase were plated in six-well plates for 24 hours. Then, cells were exposed to specific treatments for 48 hours (PF-234I $0660.5 \mu \mathrm{mol} / \mathrm{L}$, DDP I $\mu \mathrm{g} / \mathrm{mL}$, or both). Wound closure was measured using an Olympus IX7 I at I $0 \times$ magnification and compared with control. Distances of NPC cells scrambled at 48 hours were $0.99 \pm 0.11 \mathrm{~mm}$ in plates of PF- $234 \mathrm{I} 066$ alone, $0.67 \pm 0.07 \mathrm{~mm}$ in DDPalone, and $0.33 \pm 0.05 \mathrm{~mm}$ in combination, which is shorter than in the control group $(P<0.05)$. (B) PF-2341066 inhibited invasion of NPC cells. HNE-I cells were suspended in serum-free media at a density of $2 \times 105$ cells $/ \mathrm{mL}$. One hundred microliters of suspended cells and $100 \mu \mathrm{L}$ media with designated control or drugs were added to each migration chamber (PF-234I 066 $0.5 \mu \mathrm{mol} / \mathrm{L}$, DDP I $\mu \mathrm{g} / \mathrm{mL}$, or both). The cell-containing chambers were immersed in a lower chamber containing media with $10 \%$ fetal bovine serum and were incubated for 40 hours at $37^{\circ} \mathrm{C}$. The number of migrated cells was quantified using Image-Pro plus software over a composite of five microscope images. Compared to the control group, a statistically significant reduction in cell invasion was demonstrated $(79 \pm I 3$ versus $235 \pm 3 I, P<0.00 I)$ after treatment with both PF-234I 066 and DDP for 48 hours.

Abbreviations: DDP, cisplatin; NPC, nasopharyngeal carcinoma.

the biological behaviors of NPC and new targets to seek better treatment for this devastating disease is necessary. Met is a $190 \mathrm{kDa}$ receptor-like tyrosine kinase, and it is the only known high-affinity receptor for HGF in humans. Recently, studies demonstrated that activation of HGF/Met pathway played an important role in a variety of tumors. ${ }^{23}$ HGF is secreted primarily by mesenchymal cells, especially by fibroblasts, and signals through ligation with Met in a paracrine manner. ${ }^{24}$ HGF induces Met dimerization activating the tyrosine kinase by phosphorylation of tyrosine residues and cascade activation of various cytoplasmic effector proteins, including GAB1, GRB2, phospholipase $\mathrm{C}$, and SRC, and further activation of downstream signaling pathways such as $\mathrm{P} 13 \mathrm{~K} / \mathrm{AKT} / \mathrm{mTOR}$, Ras/Raf/Merk/ERK, and STAT3 that affect cell growth and 

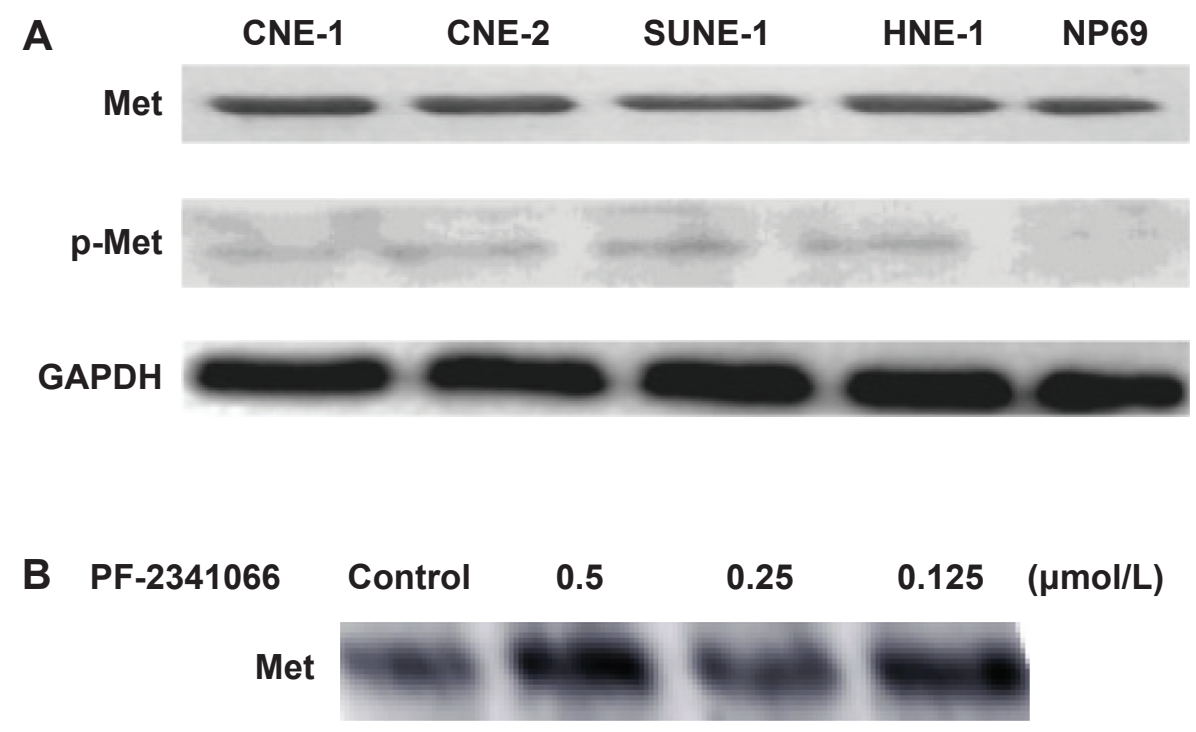

AKT

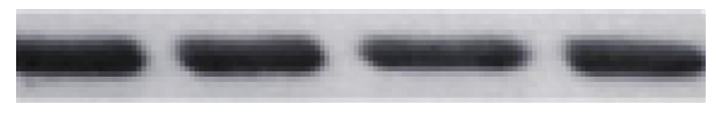

p-AKT

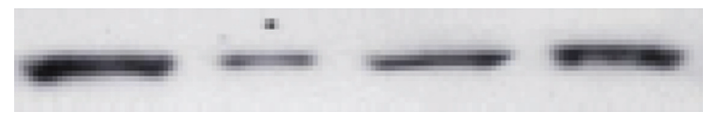

ERK

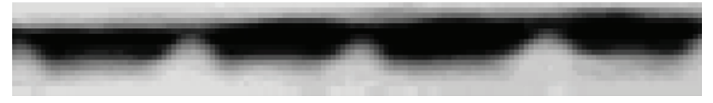

p-ERK

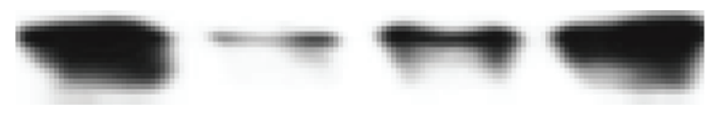

Vimentin

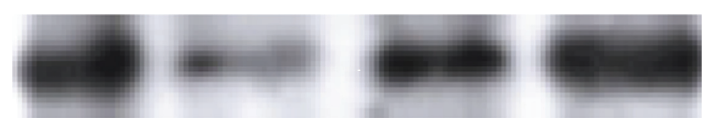

Snail

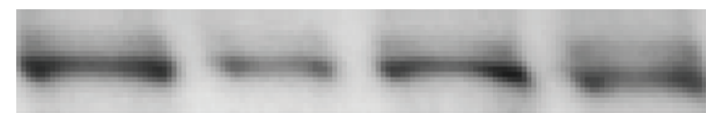

GAPDH

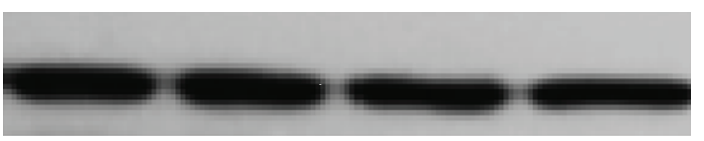

Figure 3 PF-234I 066 downregulated activation of Met signaling pathway in HNE-I.

Notes: (A) Expression and activation of Met in NPC cell lines. Expression of Met in NPC was examined by Western blot. Total Met and, phosphorylated Met was tested after treatment with $50 \mathrm{ng} / \mathrm{mL}$ HGF for 24 hours, and GAPDH is shown as control. Met expression can be found in all NPC cell lines and the normal epithelial cell line NP69, but phosphorylated Met was only detected in NPC cells. (B) Western blot of cell lines. NPC cells were serum-starved for 12 hours followed by treatment with increasing concentrations of PF-2341066 and stimulated with $50 \mathrm{ng} / \mathrm{mL}$ HGF for 24 hours. The expression of phosphorylated Met, AKT, and ERK were reversed compared with the control group. The expression of Snail and vimentin were also inhibited, which was proved to be related with epithelial mesenchymal transition.

Abbreviations: GAPDH, glyceraldehyde 3-phosphate dehydrogenase; NPC, nasopharyngeal carcinoma. 

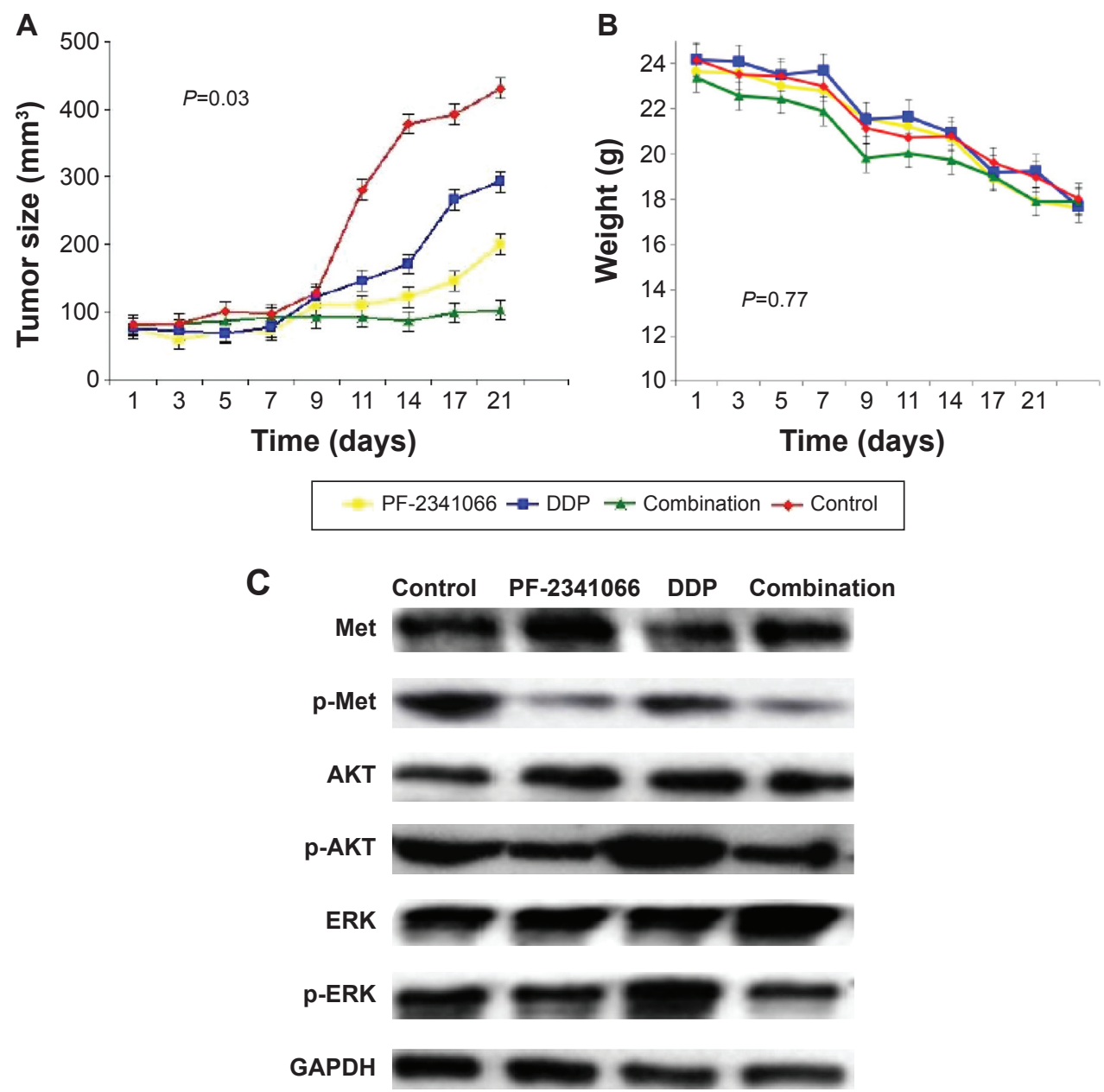

Figure 4 The antitumor effect of PF-2341066 in vivo.

Notes: NPC cells (two $\times 106)$ were injected into nude mice, and 7 days later tumors were measured and divided into four groups randomly and kept for 3 weeks. The PF-2341066 group was given 50 mg/kg/d PF-2341066 by oral gavages; the DDP group was injected intraperitoneally with I mg/kg/d DDP; the combination group was given both PF-234I066 and DDP in the above concentrations; the control group was given gavages with sterile water and injected with normal saline. (A) PF-234I066 inhibited NPC xenograft growth. (B) PF-2341066 had little effect on mice weight loss. (A and B) Tumor volume and mice weights were measured every 2 days. The inhibition rate is highest in the combination group $(P=0.03)$ while there was no statistical difference in weight loss $(P=0.77)$. (C) Western blot of Met signaling pathway in xenograft. PF-2341066 not only inhibited the phosphorylation of Met, AKT, and ERK, but also enhanced inhibition of HGF/Met signaling pathway of DDP treatment.

Abbreviations: DDP, cisplatin; GAPDH, glyceraldehyde 3-phosphate dehydrogenase; NPC, nasopharyngeal carcinoma.

invasion ultimately. ${ }^{25}$ Met activation can occur through several molecular mechanisms, including gene mutation or amplification, protein overexpression, and a ligand-dependent autocrine or paracrine loop. ${ }^{26}$ In vitro, we showed that Met pathway in all NPC cells was activated by exogenous HGF and could be

Table I Metastatic sites of mice

\begin{tabular}{lll}
\hline Group & $\begin{array}{l}\text { Liver metastasis } \\
(\text { mean } \pm \text { SD) }\end{array}$ & $\begin{array}{l}\text { Lung metastasis } \\
(\text { mean } \pm \text { SD) }\end{array}$ \\
\hline PF-234I066 & $5.8 \pm 2.2$ & $2.3 \pm 1.5$ \\
DDP & $7.3 \pm 1.7$ & $8.8 \pm 2.4$ \\
Combination & $3.5 \pm 2.5$ & $3.1 \pm 2.6$ \\
Control & $11.8 \pm 2.2$ & $5.3 \pm 0.9$ \\
$P$-value & 0.03 & 0.06 \\
\hline
\end{tabular}

Notes: PF-234I066 inhibited lung and liver metastases of mice. Compared with control group, the number of lung and liver metastases was significantly reduce in the combination group.

Abbreviation: DDP, cisplatin. reversed by Met inhibitor, PF-2341066. In addition, we found c-Met and HGF were both overexpressed in NPC tissues, and the expression of c-Met was related to metastasis and prognosis, which was consistent with previous reports on other tumors such as lung cancer and breast cancer. ${ }^{27}$ Met amplification and point mutation is not yet reported in NPC. ${ }^{28}$ Thus, we assumed that Met was predominantly activated by HGF in the tumor tissue (the so called "tumor microenvironment"), which was the same as most HNSCCs. ${ }^{29}$ These findings suggested that the Met pathway played an important role in the growth and survival of NPC, and it was a driver signaling pathway similar to other tyrosine kinase pathways, such as EGFR-induced pathway, making it a potential target for therapy.

PF-2341066 is a well-known, effective, orally bioavailable inhibitor of the Met kinase. Our research revealed that PF-2341066 inhibited the growth of NPC cells and displayed 

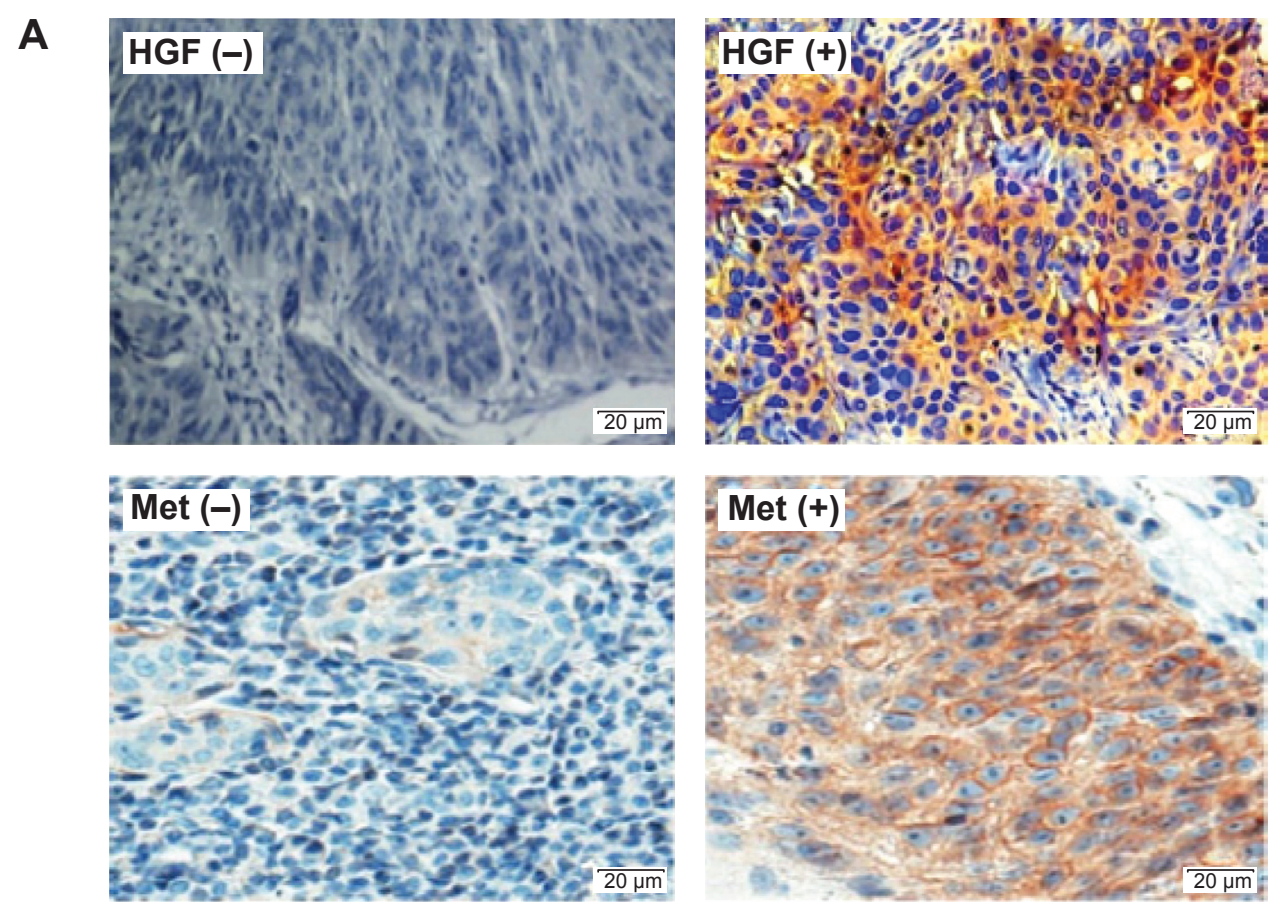

B

Survival functions

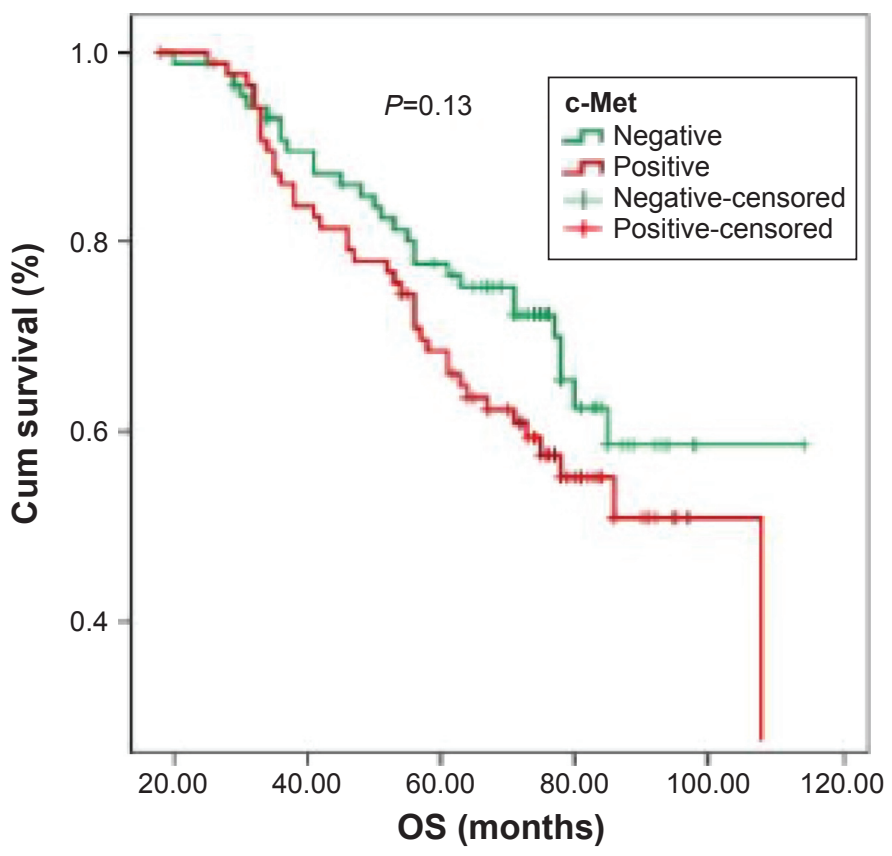

Figure 5 Expression of HGF/Met in NPC primary lesions and possible effect on OS.

Notes: (A) Expression of HGF/Met in NPC. The left panels are HGF-/Met-negative while the right panels are HGF-/Met-positive. The HGF protein was diffuse around stroma while the Met protein mainly distributed on the cell membrane. (B) The OS analysis of NPC patients. Met expression was a single prognosis factor for OS of NPC patients. Met expression positivity was more common in poor OS cases $(P=0.13)$.

Abbreviations: Cum, cumulative; NPC, nasopharyngeal carcinoma; OS, overall survival.

a synergistic effect combined with cisplatin in vitro and in vivo. Furthermore, we also proved that PF-2341066 inhibited the capacity of invasion and metastasis of NPC cells in vitro and in vivo. Western blot and immunohistochemical analysis showed that PF-2341066 inhibited activation of Met and downstream signals such as AKT and ERK. What is more, we found that Met activation in the cisplatin alone group could be inhibited in the combination group. Based on this, we speculated that HGF/Met might induced cisplatin resistance in NPC through activating 
Table 2 The expression of HGF/Met in NPC patients

\begin{tabular}{lllll}
\hline & Original site & Liver & Lung & Lymph node \\
\hline HGF & $100 \%(89 / 89)$ & $100 \%(10 / 10)$ & $100 \%(21 / 21)$ & $100 \%(21 / 21)$ \\
Met & $24.7 \%(22 / 89)$ & $40 \%(4 / 10)$ & $29 \%(6 / 21)$ & $29 \%(6 / 21)$ \\
\hline
\end{tabular}

Note: The HGF was widely expressed in NPC tissues, but the Met expression in primary lesions and metastatic lesions were significantly different, and was especially high in liver metastases.

Abbreviation: NPC, nasopharyngeal carcinoma.

downstream pathways such as PI3K/AKT and MEK/ERK, which is similar to the results found in other HNSCCs. ${ }^{30}$ It was implied that PF-2341066 could reverse the primary and acquired cisplatin resistance.

During the progression of epithelial malignance, the loss of epithelial features is often accompanied by declined contact inhibition, enhanced invasiveness, and transition to mesenchymal cells. Similar properties are shared with cells that during embryonic which is called EMT. EMT is a critical step in tumor chemotherapy resistance and metastasis. ${ }^{31}$ Downregulation of epithelial marker E-cadherin and upregulation of mesenchymal marker vimentin are key transitions in EMT. ${ }^{32}$ Also, in HNSCC, primary tumors with the low E-cadherin and high vimentin expression have a $100 \%$ metastasis rate compared to that of primary tumors with a $44 \%$ metastasis rate, which also supports the potential that these are predictive biomarker signatures for metastasis in HNSCC. ${ }^{33}$ Numerous findings showed that PI3K/AKT signaling activated NF- $\mathrm{\kappa B}$ to regulate the expression of Snail, inhibit the synthesis of E-cadherin, and then to facilitate cellular motility, as well as enhance invasiveness, ${ }^{34}$ and Snail is also the key mesenchymal marker in EMT of HNSCC and promotes EMT. ${ }^{35}$ Our study indicated that PF-2341066 downregulated Snail and vimentin by repressing Met signaling pathway, and then inhibited AKT activation. These results confirmed that inhibition of Met signaling pathway could not only inhibit the cell proliferation but also suppress EMT in NPC.

Most importantly, our findings of HGF/Met in primary lesions and metastatic lesions in NPC patients indicated that HGF was widely expressed in NPC. However, the expression of Met in primary lesions was lower than metastatic lesions and the highest expression was observed in liver metastatic lesions, thus suggesting activation of Met signaling pathway was closely related to enhanced invasiveness and metastasis. Meanwhile, previous researches demonstrated that patients with liver metastases had poorer prognosis and survival than those with other metastases, which meant patients with distant metastases, especially liver metastases, were most likely to benefit from Met-targeted therapy.
Our study is one of very few preclinical studies of the HGF/Met impact on invasion and metastasis of NPC. We found that Met expression in NPC primary tumors and metastases have significant differences, which implies that HGF/ Met pathway may play an important role in the invasion and metastasis of NPC. Further test in vitro and in vivo studies show that Met inhibitor PF-2341066 can inhibit activation of AKT and MAPK, reduce vimentin and Snail expression, and thus inhibit the EMT of NPC, which affects the cell's ability of proliferation, invasion, and metastasis. Our study suggests that HGF/Met signaling plays an important role in the development of NPC. Using only one cell line is one of the limitations of our study. It is not known whether other cell lines would respond differently to PF-2341066 or yield additional insights in the differential response to Met inhibition. Furthermore, there are potentially multiple chemotherapies for reinforcing the activity of the Met inhibitors that have not yet been tested. Despite these limitations, this study is the first to describe the use of Met inhibition in NPC, suggesting a potential role for PF-2341066 in the treatment of NPC in the future.

\section{Acknowledgments}

Pfizer supplied the drug PF-2341066 used in this study but did not participate in the development of the protocol, the running of the trial, or analysis of results. This work was also supported by the Natural Science Foundation of Guangdong Province, People's Republic of China (2014A030310030).

\section{Author contributions}

All authors contributed toward data analysis, drafting and revising the paper and agree to be accountable for all aspects of the work.

\section{Disclosure}

The authors report no conflicts of interest in this work.

\section{References}

1. Chang ET, Adami HO. The enigmatic epidemiology of nasopharyngeal carcinoma. Cancer Epidemiol Biomarkers Prev. 2006;15(10): 1765-1777.

2. Saika K, Yako-Suketomo H. Worldwide burden of cancer incidence below the age of 40 in 2002 extrapolated from the Cancer Incidence in Five Continents Vol IX. Jpn J Clin Oncol. 2013;43(3):343-344.

3. Matsuda T, Saika K. Worldwide burden of cancer incidence in 2002 extrapolated from cancer incidence in five continents Vol IX. Jpn J Clin Oncol. 2012;42(11):1111-1112.

4. Shanmugaratnam K, Sobin LH. The World Health Organization histological classification of tumours of the upper respiratory tract and ear. A commentary on the second edition. Cancer. 1993;71(8):2689-2697.

5. Chen F, Liu K, Huang QH, Liu ZW, Cao SM. [Comparison of incidence of nasopharyngeal carcinoma in populations with different fluctuation modes of immunoglobulin A antibody levels against Epstein-Barr virus capsid antigen]. Zhonghua Yu Fang Yi Xue Za Zhi. 2012;46(2):125-128. Chinese. 
6. Wei KR, Xu Y, Zhang WJ, Liang ZH, Liu J. [Trend of changes on incidence and pathological proportions of nasopharyngeal carcinoma in Zhongshan city, Guangdong province, during 1970-2007]. Zhonghua Liu Xing Bing Xue Za Zhi. 2011;32(11):1135-1138. Chinese.

7. Chan AT, Grégoire V, Lefebvre JL, et al. Nasopharyngeal cancer: EHNS-ESMO-ESTRO Clinical Practice Guidelines for diagnosis, treatment and follow-up. Ann Oncol. 2012;23 Suppl 7:vii83-vii85.

8. Lai SZ, Li WF, Chen L, et al. How does intensity-modulated radiotherapy versus conventional two-dimensional radiotherapy influence the treatment results in nasopharyngeal carcinoma patients? Int J Radiat Oncol Biol Phys. 2011;80(3):661-668.

9. Kam MK, Teo PM, Chau RM, et al. Treatment of nasopharyngeal carcinoma with intensity-modulated radiotherapy: the Hong Kong experience. Int J Radiat Oncol Biol Phys. 2004;60(5):1440-1450.

10. Ng WT, Lee AW, Kan WK, et al. N-staging by magnetic resonance imaging for patients with nasopharyngeal carcinoma: pattern of nodal involvement by radiological levels. Radiother Oncol. 2007;82(1): $70-75$.

11. Colaco RJ, Betts G, Donne A, et al. Nasopharyngeal carcinoma: a retrospective review of demographics, treatment and patient outcome in a single centre. Clin Oncol (R Coll Radiol). 2013;25(3):171-177.

12. Baujat B, Audry H, Bourhis J, et al. Chemotherapy in locally advanced nasopharyngeal carcinoma: an individual patient data meta-analysis of eight randomized trials and 1,753 patients. Int J Radiat Oncol Biol Phys. 2006;64(1):47-56.

13. Chang JT, Ko JY, Hong RL. Recent advances in the treatment of nasopharyngeal carcinoma. J Formos Med Assoc. 2004;103(7):496-510.

14. Al-Sarraf M, LeBlanc M, Giri PG, et al. Chemoradiotherapy versus radiotherapy in patients with advanced nasopharyngeal cancer: phase III randomized Intergroup study 0099. J Clin Oncol. 1998;16(4): 1310-1317.

15. Chua DT, Wei WI, Wong MP, Sham JS, Nicholls J, Au GK. Phase II study of gefitinib for the treatment of recurrent and metastatic nasopharyngeal carcinoma. Head Neck. 2008;30(7):863-867.

16. Hui EP, Ma BB, King AD, et al. Hemorrhagic complications in a phase II study of sunitinib in patients of nasopharyngeal carcinoma who has previously received high-dose radiation. Ann Oncol. 2011;22(6):1280-1287.

17. Chan AT, Hsu MM, Goh BC, et al. Multicenter, phase II study of cetuximab in combination with carboplatin in patients with recurrent or metastatic nasopharyngeal carcinoma. J Clin Oncol. 2005;23(15): 3568-3576.

18. Luo L, Yao Y, Li F. Expression of $\beta$-catenin, HGF and its receptor c-Met in nasopharyngeal carcinoma. Zhongguo Xiandai Yixue Zazhi. 2008;24:3584-3587.

19. Li Z, Lin SX, Liang HZ, He JH. [Expression of hepatocyte growth factor/c-Met system in nasopharyngeal carcinoma and its biological significance]. Zhonghua Bing Li Xue Za Zhi. 2005;34(2):75-79. Chinese.
20. Appleman LJ. MET signaling pathway: a rational target for cancer therapy. J Clin Oncol. 2011;29(36):4837-4838

21. Cui JJ. Targeting receptor tyrosine kinase MET in cancer: small molecule inhibitors and clinical progress. $J$ Med Chem. 2014;57(11): 4427-4453.

22. Zillhardt M, Christensen JG, Lengyel E. An orally available smallmolecule inhibitor of c-Met, PF-2341066, reduces tumor burden and metastasis in a preclinical model of ovarian cancer metastasis. Neoplasia. 2010;12(1):1-10.

23. Jung KH, Park BH, Hong SS. Progress in cancer therapy targeting c-Met signaling pathway. Arch Pharm Res. 2012;35(4):595-604.

24. Nakamura T, Sakai K, Nakamura T, Matsumoto K. Hepatocyte growth factor twenty years on: Much more than a growth factor. J Gastroenterol Hepatol. 2011;26 Suppl 1:188-202.

25. Lai AZ, Abella JV, Park M. Crosstalk in Met receptor oncogenesis. Trends Cell Biol. 2009;19(10):542-551.

26. Gherardi E, Birchmeier W, Birchmeier C, Vande Woude G. Targeting MET in cancer: rationale and progress. Nat Rev Cancer. 2012;12(2): 89-103.

27. Tulalamba W, Janvilisri T. Nasopharyngeal carcinoma signaling pathway: an update on molecular biomarkers. Int J Cell Biol. 2012;2012: 594681.

28. Qian CN, Guo X, Cao B, et al. Met protein expression level correlates with survival in patients with late-stage nasopharyngeal carcinoma. Cancer Res. 2002;62(2):589-596.

29. Knowles LM, Stabile LP, Egloff AM, et al. HGF and c-Met participate in paracrine tumorigenic pathways in head and neck squamous cell cancer. Clin Cancer Res. 2009;15(11):3740-3750.

30. Wang F, Arun P, Friedman J, Chen Z, Van Waes C. Current and potential inflammation targeted therapies in head and neck cancer. Curr Opin Pharmacol. 2009;9(4):389-395.

31. Thompson EW, Newgreen DF, Tarin D. Carcinoma invasion and metastasis: a role for epithelial-mesenchymal transition? Cancer Res. 2005;65(14):5991-5995; discussion 5995.

32. Zeisberg M, Neilson EG. Biomarkers for epithelial-mesenchymal transitions. J Clin Invest. 2009;119(6):1429-1437.

33. Nijkamp MM, Span PN, Hoogsteen IJ, van der Kogel AJ, Kaanders JH, Bussink J. Expression of E-cadherin and vimentin correlates with metastasis formation in head and neck squamous cell carcinoma patients. Radiother Oncol. 2011;99(3):344-348.

34. Julien S, Puig I, Caretti E, et al. Activation of NF-kappaB by Akt upregulates Snail expression and induces epithelium mesenchyme transition. Oncogene. 2007;26(53):7445-7456.

35. Zidar N, Gale N, Kojc N, et al. Cadherin-catenin complex and transcription factor Snail-1 in spindle cell carcinoma of the head and neck. Virchows Arch. 2008;453(3):267-274. 


\section{Supplementary material}

Table SI The clinical characteristics of patients

\begin{tabular}{|c|c|c|}
\hline Characteristic & Result & Percent (\%) \\
\hline \multicolumn{3}{|l|}{$\operatorname{Sex}(n)$} \\
\hline Male & 71 & 80.3 \\
\hline Female & 18 & 19.7 \\
\hline \multicolumn{3}{|l|}{ Age (years) } \\
\hline Median & 45 & N/A \\
\hline $95 \% \mathrm{Cl}$ & $21-75$ & $\mathrm{~N} / \mathrm{A}$ \\
\hline \multicolumn{3}{|l|}{ Type (n) } \\
\hline WHO III & 89 & 100 \\
\hline \multicolumn{3}{|l|}{ Tumor stage (n) } \\
\hline III & 47 & 52.6 \\
\hline $\mathrm{IVa}$ & 42 & 47.4 \\
\hline
\end{tabular}

Notes: We collected $7 \mathrm{I}$ male and 18 female patients in Sun Yat-Sen University Cancer Center during 2000-2009 who were diagnosed with local advanced tumor, and received radiotherapy later. All of them were pathologically confirmed as nasopharyngeal carcinoma type III with a median age of 45 years.

Abbreviations: WHO, World Health Organization; N/A, not applicable; $\mathrm{Cl}$, confidence interval.

\section{Publish your work in this journal}

Drug Design, Development and Therapy is an international, peerreviewed open-access journal that spans the spectrum of drug design and development through to clinical applications. Clinical outcomes, patient safety, and programs for the development and effective, safe, and sustained use of medicines are a feature of the journal, which has also been accepted for indexing on PubMed Central. The manuscript management system is completely online and includes a very quick and fair peer-review system, which is all easy to use. Visit http://www.dovepress.com/testimonials.php to read real quotes from published authors.

Submit your manuscript here: http://www.dovepress.com/drug-design-development-and-therapy-journal 